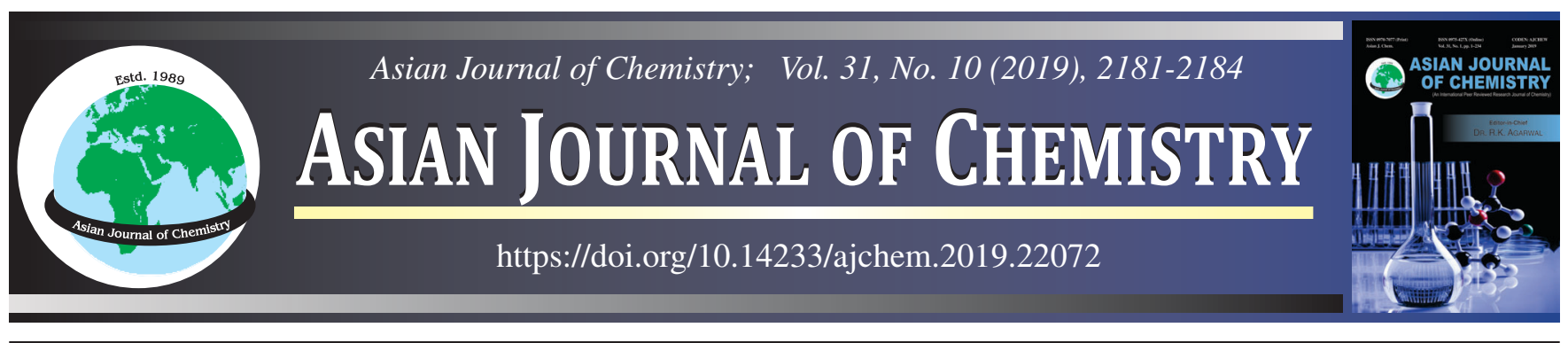

\title{
Simple Protocol for the Knoevenagel Condensation Under Solvent Free Conditions using Tungstophosphoric Acid as Catalyst
}

\author{
Abdulrahman I. Alharthi ${ }^{10}$
}

Department of Chemistry, College of Science and Humanities, Prince Sattam Bin Abdulaziz University, P.O. Box 83, Al-Kharj 11942, Saudi Arabia Corresponding author: E-mail: a.alharthi@psau.edu.sa

The effect of calcination on the performance of tungstophosphoric acid for the product of Knoevenagel condensation was investigated Substituted aldehydes and dimedone has been used in the presence of calcined tungstophosphoric acid as a heterogeneous catalyst using grinding method at room temperature. The results of reactions revealed that calcined tungstophosphoric acid has superior catalytic activity comparing to non-calcined catalyst in terms of yield and reaction time. Maximum yield of model compound was achieved by using $10 \mathrm{~mol} \%$ of calcined catalyst in a reaction time that does not exceed $10 \mathrm{~min}$, whereas the yield at same amount of non-calcined catalyst was $86 \%$ in a reaction time of $35 \mathrm{~min}$.

Keywords: Tungstophosphoric acid, Knoevenagel condensation, Calcination, Catalyst.

\section{INTRODUCTION}

Knoevenagel condensation is one of the most important organic reactions [1]. The reaction is generally performed between condensation of active methylene and carbonyl compounds in presence of some basic [2,3] or Lewis acid catalyst [4-8]. The Knoevenagel condensation products are further used in various organic reactions such as Michael additions and Diels-Alder reactions [9]. It has many applications including therapeutic drugs, perfumery, cosmetics, polymers and insecticides [10].

Heteropoly acid (HPA) has special Keggin structure having bronsted acid properties which has been used in many organic reactions $[11,12]$. Tungstophosphoric acid is one of the most important members of heteropoly acid family having high thermal as well as high solubility in polar solvents [13]. Upon calcinations, acidity of tungstophosphoric acid is increased and acidic points on the surface developed [14,15].

In the present work, tungstophosphoric acid catalyst was calcined and used for the synthesis of Knoevenagel condensation product. Selected compounds were evaluated on the basis of catalyst amount, yield and reaction time by running two parallel reactions for calcined as well as non-calcined tungstophosphoric acid.

\section{EXPERIMENTAL}

Calcination of catalyst: An accurately weighed tungstophosphoric acid was placed in a crucible and transferred in a tube furnace for calcination at around $300{ }^{\circ} \mathrm{C}$ upto $4 \mathrm{~h}$.

General procedure for the synthesis of benzylidene derivatives (3a-f) via one-pot two component reaction using tungstophosphoric acid: A mixture of aldehydes (2 mmol) and dimedone $(2.5 \mathrm{mmol})$ were grounded in the presence of varying mol \% of calcined as well as non-calcined tungstophosphoric acid at room temperature. The resulting product was obtained by recrystallization of ethanol (Scheme-I).

\section{Spectral data of few selected compounds}

2-(4-Chlorobenzylidene)-5,5-dimethylcyclohexane-1,3dione (3c): White, m.p.: $240{ }^{\circ} \mathrm{C}$, m.f. $\mathrm{C}_{15} \mathrm{H}_{15} \mathrm{O}_{2} \mathrm{Cl}$. FT-IR (ATR, $\left.V_{\max }, \mathrm{cm}^{-1}\right) ; 2950(\mathrm{C}=\mathrm{H}), 1678,1658(2 \mathrm{C}=\mathrm{O}), 1623(\mathrm{C}=\mathrm{C}) ;{ }^{1} \mathrm{H}$ NMR (DMSO, $\delta$ ppm): 7.95 (s, 1H, CH=), 7.17-7.29 (4H, m, Ar-H); ${ }^{13} \mathrm{C}$ NMR (DMSO, $\delta$ ppm): 196.59, 163.56, 143.72, 130.39, 128.31, 114.42, 50.42, 32.34, 31.41, 29.07, 26.95.

2-(4-Methoxybenzylidene)-5,5-dimethylcyclohexane1,3-dione (3d): Yellowish white, m.p.: $250{ }^{\circ} \mathrm{C}$, m.f. $\mathrm{C}_{16} \mathrm{H}_{18} \mathrm{O}_{3}$. FT-IR (ATR, $\left.v_{\max }, \mathrm{cm}^{-1}\right): 2957(\mathrm{C}=\mathrm{H}), 1677,1607(2 \mathrm{C}=\mathrm{O})$,

This is an open access journal, and articles are distributed under the terms of the Attribution 4.0 International (CC BY 4.0) License. This license lets others distribute, remix, tweak, and build upon your work, even commercially, as long as they credit the author for the original creation. You must give appropriate credit, provide a link to the license, and indicate if changes were made. 


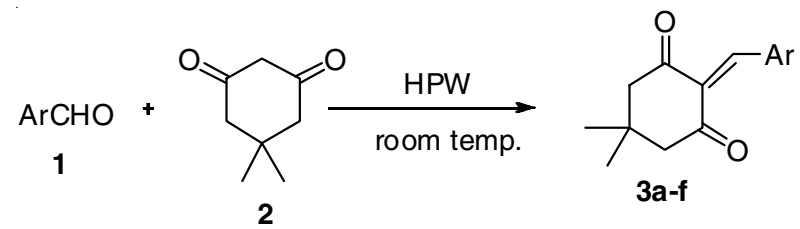

Scheme-I: Synthesis of benzylidene derivatives (3a-f) from a aromatic aldehydes (1) and dimedone (2)

$1584(\mathrm{C}=\mathrm{C}) ;{ }^{1} \mathrm{H}$ NMR (DMSO, $\left.\delta \mathrm{ppm}\right): 7.89$, (s, $\left.1 \mathrm{H}, \mathrm{CH}=\right)$, 6.76-7.07 (4H, m, Ar-H); ${ }^{13} \mathrm{C}$ NMR (DMSO, $\delta$ ppm): 196.58 , $163.14,158.00,136.88,129.45,115.06,113.68,55.37,50.51$, $32.32,30.74,29.14,26.93$.

5,5-Dimethyl-2-(2,4,6-trimethoxybenzylidene)cyclohexane-1,3-dione (3e): White, m.p.: $207^{\circ} \mathrm{C}$, m.f. $\mathrm{C}_{18} \mathrm{H}_{22} \mathrm{O}_{5}$. FT-IR (ATR, $\left.v_{\max }, \mathrm{cm}^{-1}\right): 2955(\mathrm{C}=\mathrm{H}), 1665,1625(2 \mathrm{C}=\mathrm{O})$, $1591(\mathrm{C}=\mathrm{C}) ;{ }^{1} \mathrm{H}$ NMR (DMSO, $\left.\delta \mathrm{ppm}\right): 7.26$ (s, 1H, $\mathrm{CH}=$ ), 6.41-6.61 (2H, m, Ar-H); ${ }^{13} \mathrm{C}$ NMR (DMSO, $\delta$ ppm): 196.69, $163.53,152.80,140.36,136.38,114.71,105.84,60.37,56.23$, 50.50, 32.33, 31.63, 29.16, 26.81.

2-(Indoline-3ylmethylene)-5,5-dimethylcyclohexane1,3-dione (3f): Light pink, m.p.: $112^{\circ} \mathrm{C}$, m.f. $\mathrm{C}_{17} \mathrm{H}_{19} \mathrm{NO}_{2}$. FTIR (ATR, $\left.v_{\max }, \mathrm{cm}^{-1}\right): 2930(\mathrm{C}=\mathrm{H}), 1631,1611(2 \mathrm{C}=\mathrm{O}), 1575$ $(\mathrm{C}=\mathrm{C}) ;{ }^{1} \mathrm{H}$ NMR (DMSO, $\left.\delta \mathrm{ppm}\right): 8.29$ (s, $\left.1 \mathrm{H}, \mathrm{CH}=\right), 7.20-$ 8.10 (4H, m, Ar-H); ${ }^{13} \mathrm{C}$ NMR (DMSO, $\delta$ ppm): $185.45,138.94$, $137.50,123.93,122.59,121.28,112.88,102.88,32.59,28.41$.

\section{RESULTS AND DISCUSSION}

Characterization of the catalyst was performed using different techniques such as XRD, SEM and FT-IR analysis before and after calcination. The powder XRD patterns of noncalcined and calcined tungstophosphoric acid samples are illustrated in Fig. 1. From the pattern of non-calcined tungstophosphoric acid (HPW), it is obvious that there is a sharp crystalline peak at $2 \theta=5^{\circ}$ which matches with the position of tungsten metal. On the other hand, it was absent in calcined tungstophosphoric acid (HPW-Cal), which can be attributed to the evaporation of water molecules adhered before calcination. Generally, tungstophosphoric acid appeared to be more crystalline after calcination and eventually due course bronsted acid capacity increased [14].

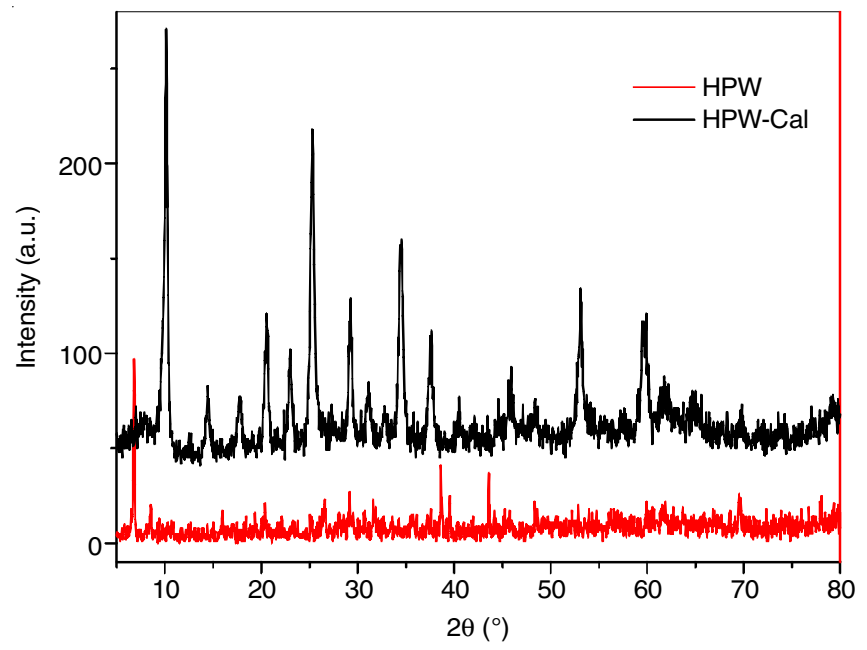

Fig. 1. Powder X-ray diffraction patterns for non-calcined (HPW) and calcined tungstophosphoric acid (HPW-Cal)
A comparative study of FT-IR for calcined (HPW-Cal) and non-calcined (HPW) sample is depicted in Fig. 2. From the IR spectra, it is evident that Kegging structure unaltered upon heat treatment [16]. A clear defined peak at 1075.48 and $963.93 \mathrm{~cm}^{-1}$ was observed for $\mathrm{P}-\mathrm{O}$ and $\mathrm{W}=\mathrm{O}$ stretching vibrations. On the other hand, a peak at $883.07 \mathrm{~cm}^{-1}$ signified for $\mathrm{W}-\mathrm{O}-\mathrm{W}$ modes of vibration.

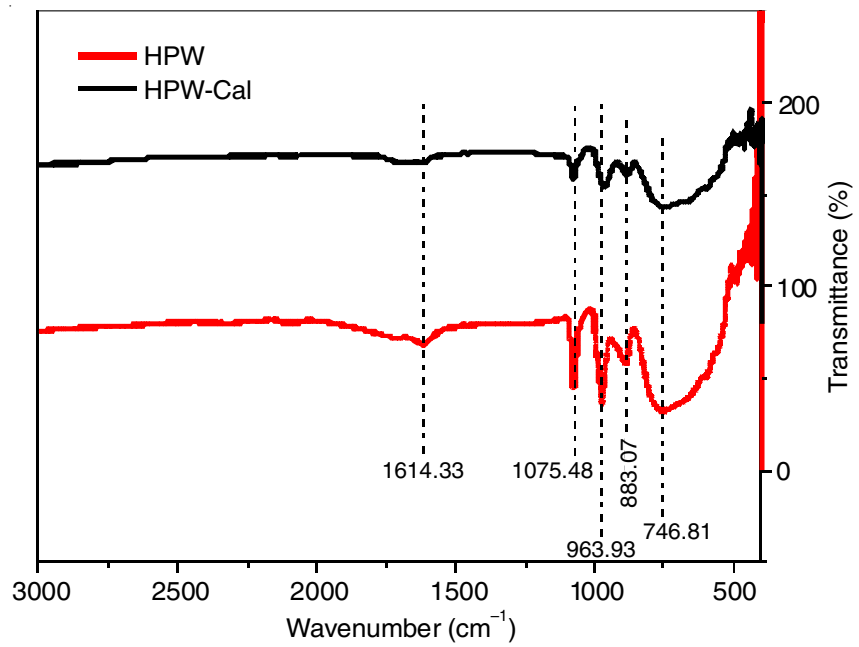

Fig. 2. FT-IR spectra analysis for non-calcined (HPW) and calcined tungstophosphoric acid (HPW-Cal)

The TGA profile for tungstophosphoric acid catalyst (HPW) is shown in Fig. 3. It can be seen that there are three weight loss regions at about 50,175 and $450^{\circ} \mathrm{C}$, respectively. The first weight loss, around $5 \%$ can be attributed to the removal of physisorbed water, whereas the second weight loss, roughly $3 \%$, can be ascribed to the bonded water to acidic protons in $\mathrm{H}_{3} \mathrm{PW}_{12} \mathrm{O}_{40}$. The weight loss beyond $450{ }^{\circ} \mathrm{C}$ was due to the loss of the remaining water molecules that corresponds to the loss of all acidic protons and the beginning of decomposition of the Keggin structure. This result is consistent with previous studies [17]. This indicates that calcination of HPW at $300{ }^{\circ} \mathrm{C}$ does not effect the structure of HPW, in good agreement with FT-IR spectrum, and increases the acidity of HPW by removal of water molecules.

SEM images for non-calcined (HPW) and calcined tungstophosphoric acid (HPW-Cal) are shown in Fig. 4. From the

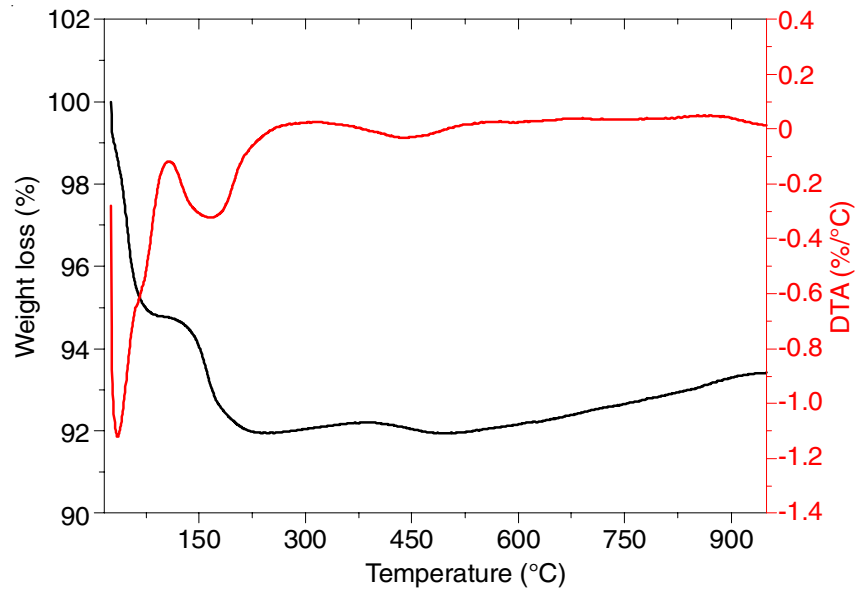

Fig. 3. TGA analysis of tungstophosphoric acid 

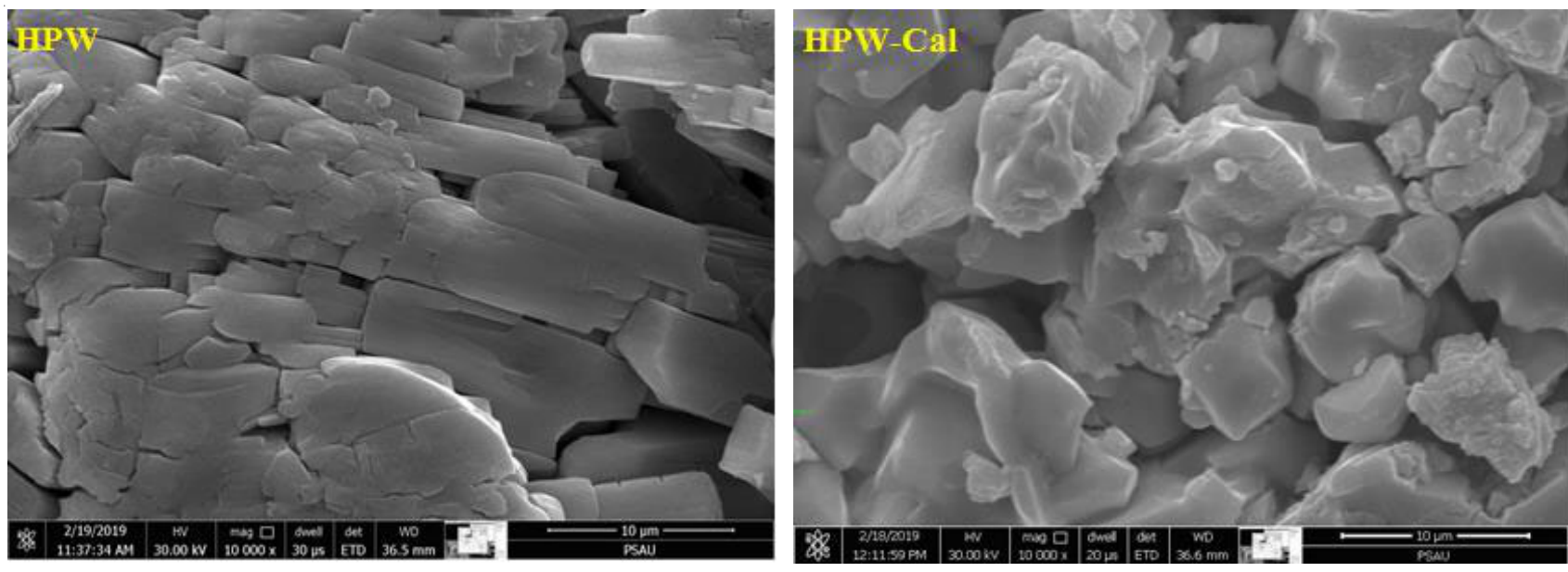

Fig. 4. SEM images of tungstophosphoric acid before (HPW) and after calcination (HPW-Cal)

images, it is possible to understand the morphology of catalyst and the changes that have been occurred on it. At the same magnification, shape of both physical forms was quite different. For non-calcined tungstophosphoric acid, it seems to be aggregated as flakes and bit amorphous. However, it was observed that calcined sample showed cubical shaped catalyst particles which support the XRD result (Fig. 1), where the particles seemed to be more crystalline.

Reaction optimization: Benzylidene derivatives (3a-f) were synthesized from aldehydes and dimedone in the presence of tungstophosphoric acid catalyst. An optimized condition was achieved using calcined and non-calcined tungstophosphoric acid. The synthesis of compound $\mathbf{3 e}$ from 2,4,6-trimethoxy benzaldehyde and dimedone was considered as a model compound to evaluate the outcome of calcined $(\mathrm{P})$ and non-calcined (Q) tungstophosphoric acid in a solvent free condition as shown in Table- 1 .

TABLE-1

EFFECT OF CALCINED (P), NON-CALCINED (Q) TUNGSTOPHOSPHORIC ACID SYNTHESIS OF MODEL COMPOUND 3e

\begin{tabular}{ccccc}
\hline Entry $^{1}$ & $\begin{array}{c}\text { Catalyst } \\
(\mathrm{mol} \%)\end{array}$ & $\begin{array}{c}\text { Yield }^{2} \\
(\%)\end{array}$ & $\begin{array}{c}\text { Time } \\
(\mathrm{min})\end{array}$ & $\begin{array}{c}\text { Temp. } \\
\left({ }^{\circ} \mathrm{C}\right)\end{array}$ \\
\hline 1 & $\mathrm{P}(4)$ & 70 & 45 & $\mathrm{RT}$ \\
2 & $\mathrm{P}(6)$ & 77 & 38 & $\mathrm{RT}$ \\
3 & $\mathrm{P}(8)$ & 85 & 25 & $\mathrm{RT}$ \\
4 & $\mathrm{P}(10)$ & 100 & 10 & $\mathrm{RT}$ \\
5 & $\mathrm{P}(15)$ & 91 & 20 & $\mathrm{RT}$ \\
6 & $\mathrm{Q}(4)$ & 55 & 60 & $\mathrm{RT}$ \\
7 & $\mathrm{Q}(6)$ & 65 & 50 & $\mathrm{RT}$ \\
8 & $\mathrm{Q}(8)$ & 74 & 42 & $\mathrm{RT}$ \\
9 & $\mathrm{Q}(10)$ & 86 & 35 & $\mathrm{RT}$ \\
10 & $\mathrm{Q}(15)$ & 78 & 40 & $\mathrm{RT}$ \\
\hline
\end{tabular}

${ }^{1}$ Reaction conditions were optimized to $100 \%$ conversion. ${ }^{2}$ Isolated yield.

The yield of product $\mathbf{3 e}$ of model reaction was increased with the amount of catalyst increased. The product yield (\%) was evaluated with the catalyst mol $\%$ and time (min). Maximum yield $(100 \%)$ of model compound was obtained using $10 \mathrm{~mol} \%$ of calcined catalyst with the less expense of time (10 min), but at the same amount of a non-calcined catalyst only $86 \%$ yield was achieved with the reaction completion time of $35 \mathrm{~min}$
(Table-1, entries 4 and 9). Again, the amount of catalyst was increased to $15 \%$ using calcined (P) and non-calcined (Q) tungstophosphoric acid and no further increase in yield was noted (entries 5 and 10). Thus, $10 \mathrm{~mol} \%$ of catalyst is the optimum amount for such reaction. Moreover, amount and physical nature of catalyst played a crucial role to get the results.

Above results also highlighted the importance of calcined (P) version of catalyst as compared to non-calcined (Q). Furthermore, catalytic activity of calcined tungstophosphoric acid can be attributed to the increase in Brønsted acid property [14,15]. To established the scope of Knoevenagel condensation reaction, aldehydes were reacted with dimedone in the presence of calcined (P) as well as non-calcined tungstophosphoric acid (Q) (Table-2).

\begin{tabular}{|c|c|c|c|c|c|c|}
\hline \multicolumn{7}{|c|}{$\begin{array}{c}\text { TABLE-2 } \\
\text { CALCINED (P) AND NON-CALCINED (Q) } \\
\text { TUNGSTOPHOSPHORIC ACID }(10 \% \text { mol }) \text { CATALYZED } \\
\text { KNOEVENAGEL CONDENSATION REACTION }\end{array}$} \\
\hline \multirow{2}{*}{ Entry } & \multirow{2}{*}{$\mathrm{R}$} & \multirow{2}{*}{ Product } & \multicolumn{2}{|c|}{ Time (min) } & \multicolumn{2}{|c|}{ Yield (\%) } \\
\hline & & & $\mathrm{P}$ & $\mathrm{Q}$ & $\mathrm{P}$ & $\mathrm{Q}$ \\
\hline 1 & & $3 a$ & 20 & 45 & 92 & 80 \\
\hline 2 & & $3 b$ & 12 & 38 & 96 & 84 \\
\hline 3 & & $3 c$ & 14 & 42 & 95 & 85 \\
\hline 4 & & 3d & 15 & 40 & 94 & 85 \\
\hline 5 & & $3 e$ & 10 & 35 & 100 & 86 \\
\hline 6 & & $3 f$ & 15 & 50 & 95 & 81 \\
\hline
\end{tabular}

Catalyst reusability: Calcined tungstophosphoric acid was further evaluated to assess the reusability ability after four runs considering model reaction under mild conditions. After reaction completion, water was added to separate the catalyst as their high solubility in aqueous system. The product was then washed again to remove any trace amount of catalyst and purified by ethanol. The catalyst recovered by first reaction 
was dried again in an oven to run for next cycle. By this technique, catalyst was reused up to 4 times without any significant loss of activity as shown in Fig. 5.

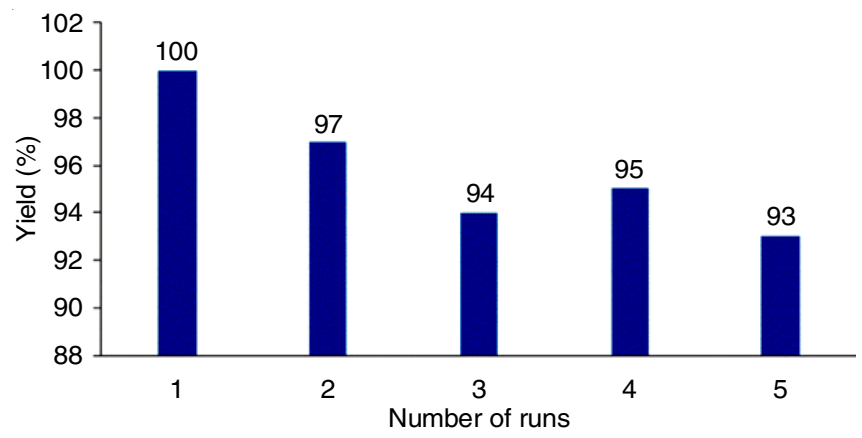

Fig. 5. Reusability of catalyst

\section{Conclusion}

A simple protocol was used for Knoevenagel condensation reactions using aldehydes and dimedone in the presence of catalytic amount of tungstophosphoric acid at room temperature under solvent-free conditions. Work-up procedure has been very easy and reaction was completed in few minutes which offered an excellent yield. In conclusion, calcined tungstophosphoric acid is found to be a better performer.

\section{CONFLICT OF INTEREST}

The authors declare that there is no conflict of interests regarding the publication of this article.

\section{REFERENCES}

1. Y. Ogiwara, K. Takahashi, T. Kitazawa and N. Sakai, J. Org. Chem., 80, 3101 (2015);

https://doi.org/10.1021/acs.joc.5b00011.
2. M.L. Deb and P.J. Bhuyan, Tetrahedron Lett., 46, 6453 (2005); https://doi.org/10.1016/j.tetlet.2005.07.111.

3. G. Jenner, Tetrahedron Lett., 42, 243 (2001); https://doi.org/10.1016/S0040-4039(00)01930-4.

4. D. Prajapati, K.C. Lekhok, J.S. Sandhu and A.C. Ghosh, J. Chem. Soc. Perkin Trans. I, 959 (1996); https://doi.org/10.1039/P19960000959.

5. G. Bartoli, R. Beleggia, S. Giuli, A. Giuliani, E. Marcantoni, M. Massaccesi and M. Paoletti, Tetrahedron Lett., 47, 6501 (2006);

https://doi.org/10.1016/j.tetlet.2006.07.031.

6. S. Kantevari, R. Bantu and L. Nagarapu, J. Mol. Catal. Chem., 269, 53 (2007); https://doi.org/10.1016/j.molcata.2006.12.039.

7. A.V. Narsaiah and K. Nagaiah, Synth. Commun., 33, 3825 (2003); https://doi.org/10.1081/SCC-120025194.

8. W. Lehnert, Tetrahedron Lett., 11, 4723 (1970); https://doi.org/10.1016/S0040-4039(00)89377-6.

9. G. Bartoli, M. Bosco, A. Carlone, R. Dalpozzo, P. Galzerano, P. Melchiorre and L. Sambri, Tetrahedron Lett., 49, 2555 (2008); https://doi.org/10.1016/j.tetlet.2008.02.093.

10. L.F. Tietze and U. Beifuss, In Comprehensive Organic Synthesis, Pergamon: New York, vol. 2, pp 341-394 (1991).

11. I.V. Kozhevnikov, Chem. Rev., 98, 171 (1998); https://doi.org/10.1021/cr960400y.

12. M. Misono, Catal. Rev., Sci. Eng., 30, 339 (1988); https://doi.org/10.1080/01614948808078622.

13. J.K. Rajput and G. Kaur, Tetrahedron Lett., 53, 646 (2012); https://doi.org/10.1016/j.tetlet.2011.11.109.

14. K. Nowiñska, R. Fiedorow and J. Adamiec, J. Chem. Soc. Faraday Trans., 87, 749 (1991); https://doi.org/10.1039/FT9918700749.

15. T. Okuhara, T. Nishimura, H. Watanabe and M. Misono, J. Mol. Catal., 74, 247 (1992); https://doi.org/10.1016/0304-5102(92)80242-9.

16. W. Klemperer and W. Shum, J. Am. Chem. Soc., 99, 3544 (1977); https://doi.org/10.1021/ja00452a080.

17. I.V. Kozhevnikov, J. Mol. Catal. A, 262, 86 (2007); https://doi.org/10.1016/j.molcata.2006.08.072. 